\title{
Juvenicidio en Córdoba (Argentina) y estrategias de biorresistencia en la acción colectiva juvenil
}

\section{Juvenicide in Córdoba (Argentina) and Bio-resistance Strategies in Collective Youth Action}

\author{
Macarena Roldán \\ Universidad Nacional de Córdoba, CIECS-CONICET-UNC \\ macarena_roldan5@hotmail.com
}

DOI: 10.24901/rehs.v40i161.659

\section{(cc) EY-NC}

Juvenicidio en Córdoba (Argentina) y estrategias de biorresistencia en la acción colectiva juvenil por Macarena Roldán se distribuye bajo una Licencia Creative Commons AtribuciónNoComercial 4.0 Internacional.

Fecha de recepción: i de enero de 2019

Fecha de aprobación: 8 de agosto de 2019

\section{RESUMEN:}

El presente artículo se propone caracterizar los procedimientos de abuso policial y de hostigamiento sistemático que afectan a jóvenes de sectores populares de Córdoba en cuanto procesos de juvenicidio, tanto en su dimensión simbólica y moral como física. Asimismo, se presenta a la Marcha de la Gorra como una acci<zón colectiva que habilita la construcción de estrategias de biorresistencia que permiten oponerse a los regímenes de opresión cotidiana, y que tienen al cuerpo de los marchantes como principal locus de realización. Ambos tópicos son abordados a partir del discurso de los propios jóvenes que participan en la Marcha. La construcción de datos se enmarca en un estudio de tipo cualitativo que empleó técnicas de registro etnográfico, observación participante, conversaciones en marcha y entrevistas en profundidad.

Palabras clave:

Acción colectiva, biorresistencia, hostigamiento policial, juvenicidio, Marcha de la Gorra. 


\section{ABSTRACT:}

This article aims to characterize the procedures of police abuse and systematic harassment that affect young people from popular sectors in Córdoba as processes of juvenicide in three dimensions: symbolic, moral and physical. At the same time, the Marcha de la Gorra is examined as a collective action that allows the construction of bio-resistance strategies that enable opposition to regimes of daily oppression, and that place participants' bodies as the main locus of realization. Both topics are pondered based on the discourse of the young people who participated in the March. The construction of these data forms part of a qualitative study based on ethnographic recording techniques, participant observation, "conversations-in-march", and in-depth interviews.

Keywords:

Collective action, bio-resistance, juvenicide, police harassment, Marcha de la Gorra.

\section{Introducción}

El concepto de juvenicidio, acuñado por Valenzuela (2015, I2) y abonado por un conjunto de autores hispanohablantes, tiene el propósito de designar la condición de exterminio o aniquilación sistemática de jóvenes (Valenzuela 2016, I). Este fenómeno de eliminación cruenta y de máxima vulneración se encuentra precedido por una diversidad de modos de violentación y precarización de las vidas juveniles que las exponen a una multiplicidad de riesgos y deterioran las condiciones en que se despliegan las trayectorias de estos sujetos.

Tales procesos de precarización adquieren características particulares en los diferentes países de la región latinoamericana. Es así que el propósito de este artículo es recuperar el concepto emergente de juvenicidio para reflexionar acerca de la situación de persecución sistemática de jóvenes de sectores populares en Córdoba, Argentina, fundamentalmente a manos de las fuerzas estatales policiales. De este modo, se discute la idea de que estas formas de violentación -que operan en conjunción con otras modalidades de violencia- exponen a los jóvenes mencionados a la posibilidad de ser impunemente asesinados por el aparato policial. Para la consecución de tal propósito se parte de la puesta en diálogo de los desarrollos teóricos de diferentes autores que abordan la problemática y la perspectiva situada de los propios actores juveniles que son el blanco preferencial de dichos procesos biopolíticos o necropolíticos, al decir de Reguillo (2015. 59).

Desde hace un tiempo a esta parte, tanto a nivel nacional como provincial, numerosos informes, denuncias y acciones de organizaciones políticas y territoriales, así como también del campo académico, se han ocupado de visibilizar y denunciar procesos de violentación a los que se ven expuestos los jóvenes de sectores populares, entre ellos, se destaca el accionar de la institución policial, que es visto permanentemente como una presencia hostil, que produce temor, rechazo y bronca entre los actores juveniles de esta porción de la población (Llobet 20I5, 
20I7; Bonvillani 20I5, 87). Las condiciones de los jóvenes para su desarrollo y para la construcción de sus proyectos de vida se encuentran fuertemente permeadas por una lógica de inclusión-exclusión en la que se anudan pliegues de desprotección y de vulnerabilidad que atraviesan sus vidas cotidianas (Capriati 2015, I32), producto del desigual acceso a los bienes sociales, políticos, culturales, económicos, entre otros.

De acuerdo con diferentes estudios llevados a cabo en el territorio cordobés, inscriptos en el campo de las ciencias sociales, los jóvenes de sectores populares se ven particularmente expuestos a procesos de persecución y violencia policial (Crisafulli 20I3, I; Plaza y Morales 20I3, I25; Bonvillani 2015, 26). Esta secuencia de hostigamiento puede enmarcarse, a su vez, en una serie de violencias estatales que opera en las diferentes esferas de la vida cotidiana de estos grupos poblacionales y que se hacen evidentes en la vulneración de un conjunto de derechos sociales entre los que se incluyen los cuidados dignos en salud, la educación de calidad, el acceso al mundo laboral, las posibilidades de habitar y usufructuar el espacio público, entre otras. En este punto, resulta pertinente realizar un breve comentario respecto del adjetivo "popular" con el que se acompaña la caracterización de los sectores juveniles a los que aquí se hace referencia. El uso deliberado de esta categoría -y no, por ejemplo, jóvenes pobres- se vincula con la pretensión de enfatizar no sólo la adscripción de clase de estos sujetos, sino también el hecho de que se trata de jóvenes que aparecen identificados con un tipo de cultura que es sistemáticamente deslegitimada desde las miradas y los discursos hegemónicos. Tales adscripciones culturales decantan en la subvaloración de determinados estilos de vida, produciendo, de esta manera, modos de estigmatización que se apoyan en imaginarios vinculados al cuerpo o al color de la piel, pero también a rasgos culturales, como se verá más adelante.

La condición de exposición descripta en las líneas precedentes, hace mella en la vida cotidiana de los jóvenes de los barrios populares de Córdoba, identificados como el blanco preferencial de las políticas punitivas de seguridad que depositan en éstos el estigma de la peligrosidad (Valdés 2013, 196; Bonvillani 2015, 9), justificando así su persecución y potencial eliminación.

Por otra parte, en un escenario cordobés que asiste a procesos de recrudecimiento del dogma securitario, y atendiendo a los cruces entre juventudes, politicidad y resistencia, resulta ineludible mencionar a la Marcha de la Gorra como una experiencia de organización juvenil sostenida por más de una década-distintiva en el campo antirrepresivo. Esta marcha consiste en una manifestación multitudinaria, ampliamente habitada por jóvenes, que se lleva a cabo un día de noviembre, en la ciudad de Córdoba. Teniendo su inicio en el año 2007, la Marcha cuenta, a la actualidad, con doce ediciones anuales, realizadas ininterrumpidamente, constituyéndose en una de las movilizaciones más convocantes del territorio cordobés. Este fenómeno de movilización reconoce como demanda de origen una fuerte denuncia de las múltiples restricciones que obstaculizan la libre circulación de los jóvenes de sectores populares en las calles de la ciudad, y que tienen como brazo ejecutor a la institución policial, traduciéndose en detenciones arbitrarias y requisas cotidianas en la vía pública (Roldán 2018, 260). Asimismo, a la par de un proceso de recrudecimiento de las políticas de seguridad cordobesas, en su vertiente más punitivista y de control, la Marcha ha ido incorporando una serie de demandas vinculadas 
con la denuncia y la visibilización de los jóvenes asesinados a manos de la policía y los operativos ilegales de irrupción violenta en los barrios periféricos de la ciudad que provocan masivas detenciones injustificadas desde el punto de vista legal.

En este sentido, se propone una elucidación de la problemática represiva y de persecución policial que acomete a los jóvenes de sectores populares en Córdoba-caracterizable en términos de juvenicidio simbólico, moral y, en los casos más extremos, físico-, para luego presentar a la Marcha de la Gorra en tanto acción colectiva que aloja procesos de biorresistencia (Valenzuela 2015b, 30) frente a dicho escenario de vulneración.

El concepto de juvenicidio y sus dimensiones de expresión

De acuerdo con Valenzuela (20I5a, 2I), América Latina asiste a procesos de pauperización de la vida de los jóvenes y a una ampliación de su fragilidad económica y social que conducen al aumento de su indefensión ciudadana, producto de la profundización de modelos económicopolíticos de corte netamente neoliberal. Previamente, otros estudiosos ya advertían que la noción de juventud se construía anudada a una serie de atributos que la vinculan con la peligrosidad, naturalizando la violencia institucionalizada que se opera contra los jóvenes, particularmente, con aquellos que se ubican en condiciones de pobreza (Reguillo 2003, 25). Así, estos autores (Valenzuela 2015a, I2 y Reguillo 2015, 59) acuñan el concepto de juvenicidio para referirse a procesos que implican no sólo el potencial exterminio físico de los jóvenes, sino que también se traduce en una operación de persecución y hostigamiento que limita las condiciones para su desarrollo singular y colectivo.

El juvenicidio implica una condición persistente, sistemática; está constituido por un conjunto de elementos que incluyen la precarización, la pobreza, la desigualdad y la estigmatización que signan las trayectorias vitales de estos jóvenes. Tales condiciones de precariedad, vulnerabilidad e indefensión se asientan sobre la base de ordenamientos clasistas, racistas y sobre un régimen prohibicionista que, bajo el pretexto de combatir el delito, opera como una estrategia que cercena los espacios sociales de libertad (Valenzuela 2015a, 38). En este sentido, el autor afirma que el juvenicidio se inicia con una espiral de precarización de las vidas juveniles y una amplificación de su vulnerabilidad social y económica que conduce a un aumento de su indefensión ciudadana y a un acortamiento de las opciones disponibles para desplegar sus proyectos de vida.

No obstante, lo cierto es que no todos los jóvenes están igualmente expuestos a dichos procesos de juvenicidio, sino que, para realizar un examen prudente de las desigualdades y violencias que aquí se plantean, es necesario asumir el desafío de pensar la condición juvenil en clave de interseccionalidad, atendiendo no sólo a la dimensión etaria, sino también a otros operadores ineludibles que se traducen en términos de posiciones de clase, de género, y de adscripciones territoriales y culturales que los ubican sistemáticamente en condiciones desiguales y precarias en la trama social. El juvenicidio "tiene como antecedente la obliteración de los canales de movilidad social para las y los jóvenes" (Valenzuela 20r5a, I7), por lo que la vulnerabilidad económica y social de estos sectores juveniles acaba precarizando también sus 
condiciones de acceso a la justicia, razón por la cual la gran mayoría de estos crímenes permanecen en total impunidad.

Es posible pensar que estos procesos desigualatorios dan lugar a la constitución de una trama de violencias que se hace carne en la materialidad de los cuerpos de estos jóvenes, que pasan a constituir sectores subalternos de la sociedad o identidades construidas como desacreditables. Los jóvenes campesinos, afrodescendientes, las disidencias sexuales, las poblaciones que viven en condiciones de extrema pobreza, son algunos de los grupos que están especialmente expuestos a las múltiples formas de violencia, producto de los procesos de precarización que tienen lugar a partir de las desigualdades mencionadas. Esta condición de indefensión y exposición sostenida a la violencia encuentra su forma más extrema en la eliminación física, en la interrupción abrupta del desarrollo vital, como el juvenicidio o el propio feminicidio. No obstante, esta trama de precarización de la vida se sostiene en la antesala de construcciones culturales y de sentido que configuran violencias simbólicas que se manifiestan cotidianamente en las relaciones vinculares cuerpo-a-cuerpo. Es así que, la precarización, las relaciones desiguales de poder, la pobreza y los procesos de estigmatización -como ocurre con ciertas identidades juveniles-y de estereotipia (por ejemplo, en los roles de género) configuran elementos característicos del juvenicidio y del feminicidio (Valenzuela 20I5a, I2; 20I6, I-3). Éstas constituyen expresiones máximas de genocidios sistemáticos que se apuntalan en condiciones de subalternidad respecto de un régimen de dominación violento, ya sea por el establecimiento de un orden patriarcal o, en este caso, adultocrático. Para explicar la inscripción última de estas vidas y estos cuerpos juveniles en tanto "sacrificables", Valenzuela (20I6, ro) se nutre de los desarrollos de Giorgio Agamben, echando mano de los conceptos homo sacer y nuda vida (Agamben 2010, I6). El autor plantea, así, que la vida de los jóvenes que se encuentran en situación de flagrante exposición, puede ser caracterizada como nuda vida, es decir, se trata de cuerpos eliminables, matables, sin que por esto se incurra en homicidio, pues, se trata de vidas que han sido construidas como desechables. De este modo, acuña la noción de iuvenis sacer (Valenzuela 2016, I5-16) para hacer referencia a este estado de excepción que envuelve las vidas juveniles precarizadas, tornándolas objeto de una necropolítica (Mbembe 20II, I7) dedicada a su eliminación, a su proscripción, convirtiéndolas en vidas prescindibles.

En esta línea, para comprender la persistencia de un contexto de vulnerabilidad e indefensión que permea estas existencias socialmente desacreditadas, resulta pertinente dedicar algunas líneas para reflexionar acerca del rol del Estado en tales procesos. La impericia o el desinterés de parte de las instituciones para impartir justicia sobre estos crímenes y combatir los despliegues de violencia sistemática que suponen, tornan evidente la connivencia y la responsabilidad del Estado, ya sea por acción u omisión, ampliando la precarización de estas vidas constantemente amenazadas (Mbembe 20II, 2I; Moreno Hernández 20I4, I28). De acuerdo con Urteaga y Moreno (2015, 82), el accionar del Estado puede inscribirse en un claro proceso de desciudadanización de estas existencias precarias, en clave de un estado de excepción particularizado. Dicho estado de excepción se caracteriza por la consideración de un sector de la población en tanto enemigos de la sociedad y del Estado, justificando así, una vez más, su persecución sistemática y su potencial eliminación. 
Finalmente, en orden a lo que se argumentó anteriormente, la forma más extrema de juvenicidio, que se vincula con la eliminación física de estos jóvenes, parte de un conjunto de violencias y desigualdades que socavan las condiciones vitales de estos jóvenes, ubicándolas de manera persistente en zonas de riesgo. En este sentido, es importante comprender que, antes de devenir en cuerpos sacrificables, estas identidades juveniles se ven expuestas a diversas violencias simbólicas que las enquistan progresivamente en una condición de subalternidad extrema, en consonancia con procesos políticos de exclusión social programada de la juventud (Feixa. Cabasés y Pardell 2015, 240). De esta forma, si la expresión más letal de juvenicidio -que podría recibir la denominación de juvenicidio físico-, puede ser definida como la eliminación o el asesinato artero, persistente e impune de jóvenes que se manifiesta en diferentes modalidades de persecución y exterminio, la dimensión más bien larvada, pero, en cierta forma, predisponente, estaría dada por el juvenicidio moral (Feixa, Cabasés y Pardell 2015, 235). Este último consiste en formas de exclusión que se originan en la marginación social, y convergen aquí al menos dos procesos de exclusión social concatenados: I) juvenicidio económico: la exclusión de los jóvenes del mercado laboral; y 2) juvenicidio simbólico: la estigmatización de su imagen social.

Lo que se pone en juego en el juvenicidio moral es un borramiento simbólico y subjetivo de estas vidas juveniles, en tanto que afecta su condición de sujetos sociales y políticos, a partir de la legitimación de discursos que los construyen como peligrosos, impugnando su estatus social o presentándolos exclusivamente desde lo deficitario, como un problema por resolver. De esta manera, se pone en riesgo la constitución y concreción de proyectos o estilos de vida anhelados por estos jóvenes, cercenando el ejercicio de una ciudadanía plena. Se trata, entonces, de una forma de genocidio "blando" que se materializa en las políticas de austeridad y de exclusión social y económica de los jóvenes, teniendo como consecuencia proyectos de vida truncados (Feixa, Cabasés y Pardell 20I5, 236). En esta operatoria característica de procesos de juvenicidio moral y simbólico podrían inscribirse el abuso policial, las detenciones arbitrarias, las requisas en la vía pública, entre otras formas de violencia policial que afectan a los jóvenes de sectores populares en Córdoba.

\section{Expresiones y estrategias de biorresistencia juvenil}

Tanto en los procesos de disciplinamiento como en los de resistencia, la corporalidad asume un papel preponderante, puesto que el cuerpo constituye la condición sensible de la subjetividad. En este sentido, cuando se habla de corporalidad se hace referencia a la realidad subjetiva, vivenciada o experienciada, que remite a una historia vital (Montenegro, Ornstein y Tapia 2006, I67), historia que es a su vez singular y colectiva, y que se vincula con la materialidad del cuerpo en tanto asiento de la subjetividad.

Respecto de la pregunta por el disciplinamiento de los cuerpos, Foucault $(1977,59)$ ha caracterizado el despliegue de una biopolítica sobre la población, la cual establece una serie de intervenciones y controles reguladores que procuran administrar los cuerpos y gestionar la vida. No obstante, en la visión de este pensador, la potencia vital nunca queda completamente atrapada en esta invasión del cuerpo viviente que procura gestionarlo, sino que escapa 
incesantemente deviniendo en "materia ética" que resiste, siendo esa resistencia un proceso de creación. En este sentido, Foucault piensa al poder ya no a partir de la lógica de la obediencia, sino atendiendo a las prácticas de "libertad" y a la "capacidad transformadora" que todo ejercicio de poder conlleva (Lazzarato 2000, 2). De este modo, Foucault (I979, I04) afirma que no hay nada más material que el ejercicio del poder, puesto que existe una red de biopoder que penetra el espesor de los cuerpos, y es por esto que las posibilidades de resistencia están alojadas en la propia materialidad corporal. Así, la dimensión de la resistencia se torna central en la concepción sobre el poder que se asume desde la mirada foucaultiana: "La resistencia está primero, y permanece como dominante en todas las fuerzas del proceso; obliga, bajo su efecto, a las relaciones de poder a cambiar, las determina. Considero pues que el término 'resistencia' es la palabra más importante, la palabra clave de esta dinámica” (Foucault ig84, 3I).

Las posibilidades de resistir se conjugan en la obra foucaultiana con la cualidad de lo viviente, cuya materialidad más evidente es el propio cuerpo de los sujetos. El poder pasa por y en los cuerpos, porque las fuerzas son las potencias del cuerpo (Lazzarato 2000, 4). En esta clave, resulta crucial el aporte de Valenzuela (2015b, 9), al establecer que el cuerpo no puede ser pensado exclusivamente como territorio de sometimiento y de control. Por el contrario, las prácticas de resistencia cultural y las expresiones artísticas ubican la materia viviente en un lugar de intransigencia definida, en clara oposición respecto de los mecanismos de regulación corporal. En esta dinámica de fuerzas se inscriben los procesos de biopolítica y de biorresistencia. De acuerdo con estos enfoques teóricos, los primeros tienden a la regulación de los cuerpos, en tanto que, los segundos, se refieren a los movimientos de resistencia y de novedad. En este sentido, la resistencia, particularmente la biorresistencia -tal como aquí es abordada- se ancla en la reivindicación de la vida a través del despliegue de unas prácticas corporales singulares y de la presentación fenoménica de unos cuerpos que entran en disputa con el poder biopolítico. De este modo, la corporalidad se ubica en el seno de las tensiones entre el disciplinamiento y la resistencia; y los movimientos vitales de producción juvenil, que encuentran su realización a partir de y en el cuerpo, son pensados aquí como maniobras de biorresistencia (Valenzuela 2015b, I4). La biorresistencia, en tanto ejercicio de soberanía sobre el propio cuerpo, para sí y para otros, presenta cierta fertilidad conceptual para pensar aquello que Foucault describía con respecto a la vida como la apuesta central de las luchas políticas, en tanto valor que se reivindica y se vuelve contra el sistema que pretendía controlarla (Foucault ig77, 86-87).

Un concepto que permite anudar los movimientos de resistencia con el lugar del cuerpo en la obra de Valenzuela (2015b, 8) es la noción de biocultura. Ésta es presentada como un elemento central que permite redefinir la posición de los jóvenes en la sociedad en la que viven, a partir de ubicar al cuerpo y sus repertorios de expresión en el centro de la disputa social. La corporalidad asume, así, un lugar estratégico de resistencia frente a las operatorias biopolíticas que procuran disciplinarla. De este modo, el cuerpo adquiere progresivamente un mayor protagonismo en tanto recurso de mediación cultural (Valenzuela 20r5b, q) que permite reivindicar los atributos culturales, simbólicos y corporales que se viven como propios y que son invisibilizados o deslegitimados desde los discursos hegemónicos y de consumo. Pensada desde estas coordenadas, la biocultura se refiere a los diversos modos de vivir y de (re)significar el cuerpo por parte de los actores o grupos sociales. En la biocultura permanece implicada la 
dimensión biopolítica que se expresa en operatorias de control y de disciplinamiento de los cuerpos, pero sin reducirse a ella, contemplando una multiplicidad de maneras de vivir y de significar el cuerpo, que le permiten al sujeto posicionarse en franca resistencia cultural y estética frente a la normatividad.

\section{Estrategia metodológica}

Puesto que el objetivo de este trabajo consistió en comprender e interpretar reflexivamente la perspectiva de los jóvenes respecto de los procesos de juvenicidio en que se inscriben las situaciones de violencia y abuso policial, así como también las concepciones que estos presentan sobre sus propias experiencias de organización y resistencia, la construcción y el análisis de datos se apoyaron especialmente en las producciones discursivas de los sujetos involucrados. En este sentido, se partió de un abordaje cualitativo que permitiera establecer análisis en clave interpretativo-hermenéutica y crítico-social (Martínez y Cubides 20I2, I84).

Asimismo, este trabajo de investigación se enmarca en un proyecto más amplio que ha estudiado la Marcha de la Gorra en Córdoba desde el año zor2 y que continúa su trayectoria hasta la actualidad. Las producciones analíticas aquí presentadas fueron construidas a partir de los registros etnográficos elaborados correspondientes a la $8^{\circ}$ (2014) y $9^{\circ}(2015)$ ediciones de la Marcha. La estrategia metodológica general de la que parte el estudio recibe la denominación de etnografía de evento (Bonvillani 2018, I63), y permite abordar la Marcha en tanto un lugarevento cuya particularidad radica en la fugacidad y la inestabilidad espacio-temporal que caracterizan su despliegue.

Entre las técnicas de construcción de datos empleadas se encuentran la observación participante (Guber 2004, I7I), el registro etnográfico/autoetnográfico (Blanco 20I2, 49), registro fotográfico y fílmico, y conversaciones en marcha (Bonvillani 20i8, 177), llevados a cabo in situ, así como entrevistas en profundidad (Robles 20II, 39) realizadas a posteriori de la movilización. De este modo, se cuenta con 16 conversaciones en marcha, I9 entrevistas en profundidad, y i extractos de registros etnográficos y autoetnográficos. Las entrevistas en profundidad estuvieron orientadas por un guion de temas que contempla los objetivos de investigación definidos previamente. Para éstas, se empleó un muestreo teórico capaz de convocar las diferentes "tipologías" de marchantes, contemplando: militantes de partidos políticos, militantes de organizaciones territoriales, estudiantes universitarios, artistas, jóvenes que vivieron de manera directa experiencias de abuso policial y autoconvocados.

Finalmente, el análisis de datos se apoya en el software de análisis cualitativo Atlas.ti, versión 6.2, que facilita la tarea de trabajar con grandes volúmenes de información, propiciando el establecimiento de relaciones entre los datos y favoreciendo la construcción de análisis interpretativo.

Procesos de juvenicidio en Córdoba y estrategias de resistencia

Tal como se planteó en la introducción de este trabajo, los jóvenes de sectores populares de Córdoba se ven particularmente expuestos a procesos de violentación por parte de la institución 
policial, siendo el blanco preferencial de una serie de políticas públicas de seguridad que podrían inscribirse en el paradigma de la tolerancia cero (Wacquant 2004, 3). Esta última consiste en un fenómeno contemporáneo que tiene lugar en diferentes regiones del mundo y que se configura en torno a un debilitamiento de la dimensión social del Estado y a un despliegue abierto de su brazo penal. Así, se desarrolla progresivamente una suerte de "paternalismo" punitivo -sostenido desde lógicas de vigilancia y control-, en el que se acentúa la represión contra los delitos menores y se produce una "erosión de la especificidad del tratamiento de la delincuencia juvenil" (2004, I37). De acuerdo con Wacquant $(2004,7)$, en este proceso de policiamiento del Estado y de internalización de la doxa punitiva, la arbitrariedad policial y jurídica hace mella en uno de los blancos predilectos del aparato penal, a saber, los jóvenes de las clases subalternas.

Los estudiosos de las políticas públicas de seguridad de la Provincia de Córdoba afirman que, particularmente en las últimas décadas, se ha profundizado el modelo de tolerancia cero (Plaza y Morales 20I3, II4), haciendo foco en la población juvenil y ejerciendo una regulación sobre las posibilidades de circulación en la ciudad. Estos procesos exponen a dichos sectores juveniles a múltiples formas de violencia y precarización. Asimismo, el ordenamiento de los cuerpos se apoya en una lógica policial de distribución y regulación que se materializa en el espacio público. En este sentido, la problemática del territorio se torna central. Las zonas céntricas de la ciudad aparecen vedadas para aquellos sujetos que no se ajustan a los criterios de "deseabilidad social" para la permanencia en tales espacios, quedando relegados a moverse en las periferias de la ciudad. Así, los barrios populares se ubican cada vez más distantes del centro urbano, obstaculizando aún más las posibilidades de tránsito de quienes allí residen (Boito y Michelazzo 20I4, 47). De este modo, las disposiciones urbanas y los emplazamientos barriales, en articulación con las fuerzas policiales que regulan la circulación de los cuerpos en el espacio público, dificultan el libre acceso de los jóvenes de sectores populares al centro de la ciudad. Los jóvenes entrevistados en este estudio se expresan al respecto de la siguiente manera:

Lo que se genera es cada vez más exclusión, cada vez más enojo. Yo también me pregunto mucho [...] a un joven que lo paran sistemáticamente, te paran, te paran, no hiciste ni bosta ${ }^{\mathrm{I}} \mathrm{y}$ te siguen parando, no podés ir al centro si no es con tu mamá a comprarte unas zapatillas, te juzgan por tu forma de vestir, no podés conseguir laburo, tampoco, porque encima tenés todos los antecedentes. Digo, ¿qué tipo de noción de futuro, de proyección, puede tener una persona ante una situación así?, que te han avasallado durante toda tu vida, o la resiliencia. O que de alguna manera también te va empujando a lo delictivo porque incluso ellos mismos: "che, mirá, roba para mí", la misma cana² está metida en todo lo que es la delincuencia, en realidad no hay nadie que se salve con esta política, no beneficia a nadie (Registro de entrevista con joven artista, 24 años).

El punto culminante de estos procesos de precarización quizás sea la sistemática persecución, hostigamiento, desaparición y, potencialmente, asesinato, a manos de las fuerzas estatales de seguridad. Esta situación de flagrante violación de los derechos humanos fundamentales ha sido aquí caracterizada en términos de "juvenicidio" (Valenzuela 20I5a, I2). Como bien se ha desarrollado, se trata de una categoría propuesta para designar el exterminio de determinados 
sectores juveniles, ampliando sus efectos a múltiples formas de truncar sus trayectorias vitales, más allá de la fatal supresión de sus vidas.

De este modo, se mata a los jóvenes disparándoles, pero también atentando contra su condición de auténticos ciudadanos al condicionar sus posibilidades de acceso a bienes económicos, políticos, culturales, simbólicos:

Sí, montones de veces [me detuvieron]. Cada vez que vamos a salir del barrio [...] tenemos que caminar un montón de cuadras, como veinte cuadras caminamos hasta la ruta y ahí está siempre lleno de policías. Así que, si no salimos en Trafic o en auto en algo así no podemos salir, no hay forma. Y es súper injusto, ¿viste? Porque siempre es al pobre al que se detiene [...] Y los pobres también somos ciudadanos. A mí una vez me pasó que había venido al Centro por un trabajo y me detuvieron, me tuvieron unos días detenidos [...] y no puede ser así, eso tiene que cambiar. Nosotros tenemos derecho a poder andar por la ciudad libremente como cualquiera [...] porque los pobres somos ciudadanos también (Registro de conversación en marcha con joven autoconvocado, amigo de víctima de gatillo fácil, ıg años).

En este sentido, las formas de estigmatización basadas en imaginarios vinculados al cuerpo y a las adscripciones culturales de estos jóvenes decantan en la atribución de rasgos de peligrosidad y delincuencia y se reactualizan en lo que se denomina "olfato policial" (Crisafulli 20iz, 6), dando lugar a múltiples formas de accionar arbitrario en los procedimientos policiales practicados sobre los cuerpos juveniles. En el discurso de los jóvenes, esta arbitrariedad es enunciada de la siguiente manera:

No a todos por igual ¿eh? Porque es una cuestión que, más vale que al rubio no le afecta igual que al morocho o al que le falta un diente, o al que usa gorrita, pero sí, yo estoy seguro de que acá no hay uno solo que no lo haya parado la policía, o que no conozca este tipo de prácticas o que no esté acostumbrado a que la policía puede hacer eso, puede venir y bardearte, ${ }^{3}$ y preguntarte "¿vos qué estás haciendo acá?" o "para mí vos andás robando" o "están al pedo ustedes, por eso hacen música” y qué se yo, todo este tipo de cosas que las dicen impunemente, digamos (Registro de conversación en marcha con joven murguero, 28 años).

Por otra parte, estas políticas de exclusión social programada de la juventud (Feixa, Cabasés y Pardell 20I5, 240) como forma de juvenicidio, tienen una vertiente simbólica que opera a través de la práctica policial y del imaginario social, convirtiendo a los jóvenes en víctimas de estereotipos mediáticos, policiales y adultocéntricos, habilitando y avalando prácticas de persecución y hostigamiento de parte de la policía (Bonvillani 20I5a, 26; Lerchundi y Bonvillani 20I4, 47): 
La portación de rostro 5 , que si vos salís a la esquina con una gorra de noche, o tenés un arito en la cara o tenés pinta de negro villero, te levantan, te llevan, te pintan los dedos, o te hacen lo que sea, en ese aspecto. Lo del merodeo,,$\frac{6}{q u}$ si te encuentran por ahí, también te alzan y te llevan, te hacen lo que quieren, si no tenés documento, pero ojo, sólo si estás vestido de una forma especial, no es si te ven de jean y de una camperita de cuero, ahí no te van a alzar ni te van a llevar (Registro de entrevista con joven autoconvocada, I6 años).

Y sí, el color de la piel, la gorra, el porte más de barrio, más cordobés, de las salidas también [...] dónde circulo. Por ahí son más los bailes, los barrios, más las periferias ¿no? (Registro de entrevista con joven autoconvocada, 24 años).

La expresión más extrema de estas formas de persecución de los jóvenes por parte de la policía, se materializa en los casos de "gatillo fácil", categoría local que se emplea para designar la utilización abusiva de armas de fuego por parte de las autoridades policiales (Llobet 20I5, 222). En ciertas instancias de la Marcha, el reclamo parece tener como punto de partida el cansancio, el hartazgo que clama por el cese del abuso policial, de manera tal que los casos de gatillo fácil cobran una visibilidad máxima:

Porque estamos hartos de las Yamila Cuello; porque estamos hartos de los Facundo Rivera Alegre; porque estamos hartos de los Brian Palomequez; porque estamos hartos de la represión, la persecución. (Desgrabación del micrófono oficial de la Marcha de la Gorra, 20/II/2014)

Acá estamos, una vez más, reclamando por nuestros derechos; porque nuestras convicciones están presentes en cada momento de la vida, porque decimos basta de gatillo fácil, basta de abuso, basta de femicidio, basta de acoso hacia las mujeres, basta de perseguir a los jóvenes. (Desgrabación del micrófono oficial de la Marcha de la Gorra, 20/II/20I4).

Hoy, más que nunca, estamos aquí, salimos a las calles a pedir justicia; sí, salimos a pedir justicia porque estamos cansados de ver a nuestras viejas que laburan y se matan por criarnos y educarnos, llorando la pérdida de un hijo. Por eso, hoy más que nunca, hoy esta lucha es por todos estos jóvenes asesinados por la yuta ${ }^{\underline{8}}$ corrupta de la provincia de Córdoba. [...] Acá estamos los merodeadores, los peligrosos [...] Ésta es la cultura de la juventud de Córdoba, que resiste marchando tranquilamente por las calles de Córdoba. Octava Marcha de la Gorra: más vale gorras embrollando que la policía matando (Desgrabación del micrófono oficial de la Marcha de la Gorra, 20/II/20I4).

En un escenario en el que las políticas de seguridad regulan diferencialmente el espacio público, es posible pensar la irrupción masiva de cuerpos juveniles que la Marcha de la Gorra habilita en tanto una acción colectiva contenciosa (Tarrow I997, Iq) que instala un claro litigio contra las políticas públicas de seguridad y el uso abusivo de la fuerza. Este evento consiste en 
una manifestación multitudinaria con gran participación juvenil, que tiene lugar una vez al año -desde 2007 hasta la actualidad- de manera ininterrumpida en el escenario cordobés. Esta acción de protesta conquista su nombre a partir de la identificación del objeto-símbolo "gorra", en tanto accesorio de vestuario asociado con los jóvenes de los barrios, que es rechazado por la etiqueta social hegemónica y que acaba constituyéndose en un elemento que expone a la posibilidad de ser detenido o de ser identificado como sospechoso por parte de los agentes policiales. La participación de estos jóvenes en el espacio público, tiende a desplegarse a través de diversos canales expresivos y organizativos, no necesariamente vinculados con la institucionalidad política tradicional, como es el caso de la propia Marcha. Estas modalidades de participación, novedosas e instituyentes, adoptan un componente afectivo/emocional que se hace evidente en los cuerpos de quienes participan. La Marcha se caracteriza por un despliegue colorido y lúdico que constituye su repertorio, el cual incluye una diversidad de expresiones e intervenciones artísticas, de manera tal que la corporalidad de los marchantes aparece como materialidad desde la cual se denuncia y se repudia la persecución y el abuso policial hacia los jóvenes, al tiempo que es también un locus de expresividad y celebración de la cultura juvenil y popular:

Y ya el día de la Marcha es [...] También, la salida, los colores, las murgas, el sentido de lo popular, lo transversal (Registro de entrevista con joven artista, 27 años).

La festividad, las caras sonrientes de la gente marchando por sus derechos [...] (Registro de conversación en marcha con joven autoconvocado, 23 años).

La potencia del encuentro con el otro, transmuta el dolor y la impotencia en un reclamo colectivo que avanza reivindicando la voz y el pedido de los jóvenes, de manera tal que la corporalidad se torna el locus principal desde el cual se ejerce la protesta. Se asume la producción de resistencias, particularmente, ligadas a la reivindicación de la propia vida y del propio cuerpo, como estrategias que ponen en juego estos sujetos juveniles en la experiencia politizada de la Marcha. La materialidad del cuerpo, al constituirse en el territorio a partir del cual es posible oponerse a los regímenes de opresión habilita, así, procesos de biorresistencia:

Y el final de la Marcha [...] me acuerdo que toda la gente agarraba, y creo que era gente que no se conocía, y se abrazaban y gritaban “justicia!", pedían justicia. Eso me impresionó, era gente que eran desconocidos, nosotros éramos desconocidos ahí y creo que no éramos los únicos y era como si nos conociéramos todos y luchábamos por algo en común. Y el final de la Marcha fue como que dijeron: "hay que darnos fuerza" (Registro de entrevista con joven autoconvocado, I9 años).

No sé, veo que la gente viene con ganas, pero porque se siente apoyada por el resto aquí, aunque no se conocen unos a otros, pero veo como miradas de complicidad, el mismo sentimiento en todas las personas (Registro de conversación en marcha con joven autoconvocada, 22 años). 
Pero hay un montón de gente que por lo general no ocupa los espacios públicos, o por ahí no son tan visibles y que en esta Marcha sienten como que tienen todo el protagonismo. Eso me resorprendió, me gustó (Registro de entrevista con joven autoconvocada, 29 años).

Éramos muchas personas, y eso le da una fortaleza, una garganta, una voz a la marcha, [...] algunas agrupaciones habían llevado antorchas, otras estaban con las banderas y éramos como que tenía un tinte no sé si alegre, porque no era una situación muy alegre, pero en cierta forma es una postura ante lo que te pasa (Registro de entrevista con joven militante de organización estudiantil, 22 años).

En relación con lo expuesto, es posible pensar que en las intervenciones que ponen en acto los jóvenes de la Marcha se activan modalidades de biorresistencia, atendiendo al hecho de que varios de los prejuicios por los que se los expulsa del espacio público se apuntalan en marcas corporales, y es desde allí -en la presencia viva de sus cuerpos en la calle-desde donde va a disputarse el poder (Bonvillani 20I3, 94):

Tengo la imagen de, apenas llegué, había un montón de chicos, de un barrio se ve, o de no me acuerdo qué organización, así felices, gritando, y que se sacaron una foto, y eso me re gustó [...] Esa es la sensación que más me gustó de la Marcha, sentir que se apropian del espacio, en ese momento, por lo menos [...] y que son como son, porque por ahí nosotros no vemos a los chicos de los barrios como son, como yo los veo en la escuela, ¿entendés? Siento que está todo hecho para que se tengan que cuidar, para que ciertos modales tengan que ser reprimidos, jen cambio, en la Marcha no!, en la Marcha gritaban, se sacaban fotos [...] y eso me encantó (Registro de entrevista con joven autoconvocada, 29 años).

Por otra parte, los mecanismos de resistencia bioculturales que se ponen en juego en la Marcha, se vinculan con la puesta en visibilidad y la legitimación no sólo del propio cuerpo de los jóvenes, sino también de los recursos culturales de los cuales éstos se apropian y con los que se identifican, recursos que se emplean en la acción colectiva en clave de protesta y de denuncia reivindicatoria:

Escuchabas al sonido del Colectivo [de Jóvenes], después escuchabas de una murga, después escuchabas de una organización, de un partido, todos los sonidos distintos y las canciones. Se escuchaba que en algún lugar estaba sonando La Mona ${ }^{2}$ y que en otro lugar estaban los bombos y platillos, es como todo eso en un mismo lugar. Ese lugar imantado, magnetizado, y que en ese mismo lugar hay tanto (Registro de entrevista con joven autoconvocada, 23 años). 
Ver también que hay diferentes artistas que se acercan a participar de la Marcha de la Gorra, que ponen música y que en esa música y en esas canciones también está muy bueno el reclamo y la denuncia, eso es mística (Registro de entrevista con joven militante de partido político, 22 años).

En definitiva, estas estrategias de biorresistencia que se gestan al calor de la organización colectiva son entendidas como elementos que conforman códigos del cuerpo significado y que permiten visibilizar el poder del sujeto sobre su propio cuerpo (Valenzuela 2015b, I4). Los sujetos pueden moldear la materia viviente que constituye su presentación fenoménica ante el mundo, produciendo así un instrumento vital y estratégico de reconocimiento para sí mismos y frente a los demás (Valenzuela 2015b, I4). Aparecen, entonces, formas particulares de vestimenta, accesorios -como la gorra, por ejemplo-, tatuajes, cortes de cabello, gestualidades y repertorios corporales que remiten a inscripciones colectivas, culturales y también barriales, como forma de territorialización de la corporalidad. En este contexto, se trata de intervenciones corporales que pueden ser caracterizadas como expresiones bioculturales:

Vinimos al centro a demostrar que esta es nuestra cultura, la cultura de los jóvenes, la cultura que aguanta, que resiste que la verdugueen, delincuentes que le choreen; venimos acá a demostrar lo que somos. Octava Marcha de la Gorra, esto es un embrollo, jesto! Toda esta gente acá, celebrando nuestra cultura. “Ezequiel Saldaño? Presente! Ahora [...] Y siempre! Ahora [...] Y siempre!” [...] Acá estamos los merodeadores, los peligrosos, los que la policía le gusta verduguear, a los que le gusta pedir coima, [...] Ésta es la cultura de la juventud de Córdoba que resiste marchando (Desgrabación del micrófono oficial de la Marcha de la Gorra, 20/II/20I4).

Me gustan mucho también las intervenciones artísticas de la Marcha de la Gorra, los carteles, las consignas. Es que es distinto, más allá de que en Córdoba explotamos las marchas, con cuestiones más artísticas, yo creo que es algo que fuimos armando nosotros como cordobeses en las formas de luchar, y que es muy zarpado. Y la Marcha de la Gorra reivindica todo eso [...] y mi gorra sí, yo trabajo (Registro de entrevista con joven autoconvocada, 23 años).

Esta multiplicidad de expresiones que albergan sentidos políticos y artísticos, son abordadas en este estudio como modalidades de configuraciones bioculturales que se inscriben en el cuerpo de los jóvenes, delimitando procesos de biorresistencia que les permiten reposicionarse y disputar poder respecto de las formas de opresión que signan sus vidas cotidianas, aquí entendidas como procesos de juvenicidio.

Palabras de cierre

En este artículo se procuró enmarcar la problemática del abuso policial y el hostigamiento que sufren cotidianamente los jóvenes de sectores populares de Córdoba en tanto procesos de juvenicidio que presentan tanto una dimensión moral y simbólica, como física. Asimismo, se 
presentó a la ya histórica Marcha de la Gorra como una acción colectiva que habilita estrategias de biorresistencia frente a tales formas de opresión, partiendo de la perspectiva de los propios jóvenes involucrados.

Poder caracterizar estos procesos abusivos y lacerantes para las trayectorias vitales de estos jóvenes en términos de juvenicidio tiene importantes implicancias y resulta pertinente al menos en dos sentidos: conceptual y ético-político. Por un lado, hablar de juvenicidio tiene relevancia conceptual para identificar y designar -sin incurrir en eufemismos- procesos sistemáticos de violentación, eliminación, persecución y desacreditación de ciertos grupos juveniles. Estas operatorias se consolidan en los despliegues incontrolados de violencia, con un reforzamiento de los dispositivos de militarización del Estado, a través de políticas de seguridad orientadas a combatir un enemigo interno que se particulariza en los cuerpos de los jóvenes de sectores populares. Es así como estos cuerpos/sujetos se configuran en blancos preferenciales de una maquinaria biopolítica que se sostiene a partir de una matriz racista, clasista y adultocéntrica.

No obstante, no todos los sujetos juveniles están igualmente expuestos a sufrir tales procesos de violentación, sino que la conjunción de una serie de precarizaciones (económica, social, cultural, judicial), apoyadas en el binomio biopolítica/necropolítica van configurando lo que Valenzuela (2015a I2; 2016, I8) denomina condiciones límite o zonas de riesgo. De este modo, al emplear la categoría "juvenicidio" es preciso prestar especial atención al contexto históricosocial en el que transcurren sus vidas y a cómo estos jóvenes son construidos e inscriptos simbólicamente, atendiendo particularmente a las relaciones situadas (Valenzuela 2016, 3) dentro de la amplia trama social. A partir de su ubicación en unas coordenadas de precarización y vulneración vinculadas con cuestiones étnicas y de clase, estos grupos juveniles son concebidos desde la estigmatización y el rechazo, tornando sus vidas prescindibles y matables. Esto último es lo que el autor citado denomina iuvenis sacer o la nuda vida juvenil (Valenzuela 20i6, I6), recuperando los desarrollos de Agamben.

En segundo lugar, el concepto juvenicidio presenta una incuestionable relevancia éticopolítica puesto que permite develar cierto rasgo maquinal, programado, direccionado que envuelve a las miles de muertes juveniles que han teñido con sangre la historia reciente de América Latina. Arrebatamiento cruento y progresivo de vidas juveniles que permanece velado tras un halo de impunidad, ocultamiento e invisibilización, en el que muchas veces se torna manifiesta la connivencia del Estado y del poder judicial. El término juvenicidio vuelve posible la identificación de procesos sociales y políticos, superando la construcción fragmentaria de estos asesinatos en tanto eventos aislados o como meros registros estadísticos.

Finalmente, se intentó precisar, a partir de la palabra de los propios actores juveniles, de qué modo la Marcha de la Gorra -con ya más de once años de historia- se constituye en una experiencia ineludible de organización y resistencia juvenil, en clave de movimiento antirrepresivo. La Marcha es aquí pensada como una acción colectiva que habilita la configuración de estrategias bioculturales y de biorresistencia, que operan en la territorialidad de los cuerpos juveniles que allí participan, en franca oposición al sistema de regulaciones y opresiones que vivencian cotidianamente. Podría pensarse que, en última instancia, lo que se 
pone en visibilidad en esta acción colectiva juvenil de protesta es la vida misma como derecho al cuerpo, por sobre todas las opresiones y alienaciones, en tanto "plenitud de lo posible" (Foucault I977, 86) para hallar lo que uno es -y, sobre todo, lo que puede ser-; incluso para encontrarse con la posibilidad de ser un joven cordobés de sector popular sin ser interceptado por formas simbólicas o físicas de exterminio.

\section{Bibliografía}

AGAMBEN, Giorgio. 20io. Homo Sacer. El poder soberano y la nuda vida. Valencia: PreTextos.

BLANCO, Mercedes. 20I2. "Autoetnografía: una forma narrativa de generación de conocimientos". Andamios 9(I9): 49-74. https://doi.org/I0.29092/uacm.v9ir9.390

BOITO, María Eugenia y Cecilia MICHELAZZO. 20i4. "Córdoba en pedazos. Habitar/circular en contextos sociosegregados". Estudios Sociales Contemporáneos (Io): 4558. https://rdu.unc.edu.ar/handle/IIo86/5955

BONVILLANI, Andrea. 20I3. "Cuerpos en marcha: emocionalidad política en las formas festivas de protesta juvenil”. Revista Nómadas (39): 9IIO3. http://nomadas.ucentral.edu.co/index.php/inicio/ıo-la-sensibilidad-potencia-yresistencias-nomadas-39/68-cuerpos-en-marcha-emocionalidad-politica-en-las-formasfestivas-de-protesta-juvenil

2015. Callejeando la alegría... y también el bajón. Etnografía colectiva de la Marcha de la Gorra. Córdoba: Encuentro Grupo Editor.

20I8. "Etnografía colectiva de eventos: la cronotopía paradojal de la Marcha de la Gorra (Córdoba, Argentina)". De prácticas y discursos 79): I84. https://doi.org/I0.30972/dpd.792806

CAPRIATI, Alejandro José. 2015. "Desigualdades y vulnerabilidades en la condición juvenil: el desafío de la inclusión social". Convergencia Revista de Ciencias Sociales (69): I3II50. http://www.scielo.org.mx/scielo.php?script=sci_arttext\&pid=SI405-

I43520I 500030013 I \& $\operatorname{lng}=$ es\&nrm=iso

CRISAFULLI, Lucas. 20i3. "Neo racismo latinoamericano, la seguridad como excusa y el paradigma de los Derechos Humanos". Apertura I(I): I-I4. http://hdl.handle.net/IIo86/588I

FEIXA, Carles, M. Ángels CABASÉS y Agnès PARDELL. 2015. "El juvenicidio moral de los jóvenes... al otro lado del charco". En Juvenicidio. Ayotzinapa y las vidas precarias en América Latina y España, coord. José Manuel Valenzuela. Barcelona y México: NED Ediciones.

FOUCAULT, Michel. 1977. Historia de la sexualidad I: La voluntad el saber. México: Siglo XXI Editores. 
. 1979. Microfísica del poder. Madrid: La Piqueta.

. 1984. Michel Foucault, una entrevista: Sexo, poder y la política de la identidad. Toronto: The Advocate.

GUBER, Rosana. 2004. El salvaje metropolitano. Reconstrucción del conocimiento social en el trabajo de campo. Buenos Aires: Paidos.

LAZZARATO, Maurizio. 20oo. "Del biopoder a la biopolítica". Multitudes (I): 4557. https:/es.scribd.com/doc/285882947/Maurizio-Lazzarato-Del-Biopoder-A-LaBiopolitica-pdf

LERCHUNDI, Mariana Jésica, y Andrea BONVILLANI. 20I4. "Jóvenes y Código de Faltas. Una 'experiencia' de Jetención". Justicia Juris Io(I): 52. http://www.scielo.org.co/pdf/jusju/vioni/vionia05.pdf

LLOBET, Valeria. 2015. "Políticas y violencias en clave generacional en Argentina". En Juvenicidio. Ayotzinapa y las vidas precarias en América Latina y España, coord. José Manuel Valenzuela. Barcelona y México: NED Ediciones.

MARTÍNEZ, María Cristina y Juliana CUBIDES. 20Iz. "Acercamientos al uso de la categoría de 'subjetividad política' en procesos investigativos". En Subjetividades políticas: desafíos y debates latinoamericanos, comp. Claudia Piedrahita Echandía, Álvaro Díaz Gómez y Pablo Vommaro. Bogota: Magisterio, CLACSO.

MBEMBE, Joseph-Achille. 2ori. Necropolítica. Santa Cruz de Tenerife: Editorial Melusina.

MONTENEGRO, María Angélica, Claudia ORNSTEIN y Patricia TAPIA. 2006. "Cuerpo y corporalidad desde el vivenciar femenino". Acta Bioethica I2(2): I65I68. https://actabioethica.uchile.cl/index.php/AB/article/view/I6606/17273

MORENO HERNÁNDEZ, Hugo César. 20r4. "Desciudadanización y estado de excepción". Andamios. Revista de Investigación Social II(24): I25I48. https://andamios.uacm.edu.mx/index.php/andamios/article/view/235/217

PLAZA, Valeria y Susana MORALES. 20r3. "Seguridad y democracia: Tensiones de origen. Aportes al análisis de la política de seguridad en la provincia de Córdoba". Estudios (29): IIII3I. https://revistas.unc.edu.ar/index.php/restudios/article/view/5342

REGUILLO, Rossana. 2003. "Ciudadanías juveniles en América Latina". Última Década (I9): II3o. http://dx.doi.org/Io.4067/So718-22362003000200002

2015. "La turbulencia en el paisaje: de jóvenes, necropolítica y 43 esperanzas". En Juvenicidio: Ayotzinapa y las vidas precarias en América Latina y España, coord. José Manuel Valenzuela Arce. Barcelona y México: NED Ediciones. 
ROBLES, Bernardo. 20Ir. "La entrevista en profundidad: una técnica útil dentro del campo antropofísico". Cuicuilco (52): 39-49. https://doi.org/Io.IOI6/so2I2-5382(04)71695-7

ROLDÁN, Macarena. 20I8. "Acción colectiva juvenil y procesos de subjetivación política: el caso de la Marcha de la Gorra en Córdoba (Argentina)". Methaodos. Revista de Ciencias Sociales 6(2): 252-262. http://dx.doi.org/Io.I7502/m.rcs.v6i2.248

TARROW, Sidney. 1997. El poder en movimiento. Los movimientos sociales, la acción colectiva y la política. Madrid: Alianza.

URTEAGA Maritza y Hugo César MORENO. 20I5. "Corrupción e impunidad versus justicia y Derecho en México", En Juvenicidio: Ayotzinapa y las vidas precarias en América Latina y España, coord. José Manuel Valenzuela Arce. Barcelona y México: NED Ediciones .

VALDÉS, Estela. 20iz. "Pobres y maltratados. La ciudad de Córdoba desde la segregación y las políticas públicas de seguridad ciudadana". Anuario de la Escuela de Historia Virtual (4): i87206. https://revistas.unc.edu.ar/index.php/anuariohistoria/article/view/8394/9265

VALENZUELA, José Manuel. 2015a. Juvenicidio. Ayotzinapa y las vidas precarias en América Latina y España. Barcelona y México: NED Ediciones.

-_-_. 20I5b. "Decálogo para repensar las certezas". Alternativas (4): I5r. https://www.alternativas.osu.edu/es/issues/spring-4-20r5/essays/valenzuela-arce.html

2016. "Juvenicidio: necropolítica y iuvenis sacer". En Jóvenes latinoamericanos: Necropolíticas, culturas políticas y urbanidades, coord. Silvia Borelli. Inédito: Mimeo.

WACQUANT, Löic. 2004. Las cárceles de la miseria. Buenos Aires: Manantial.

Notas

I Categoría local: "no hiciste nada".

2 Categoría local: policía.

3 Categoría local: insultarte, humillarte.

${ }_{4}$ Categoría local: ocioso, sin una ocupación definida.

5 Categoría local: forma irónica de referirse a la sobreexposición arbitraria a ser detenido en función de rasgos fisonómicos y color de la piel.

6 La figura del Merodeo era una de las más aplicadas en el marco del Código de Faltas (legislación contravencional de la provincia de Córdoba) para proceder a las detenciones de estos jóvenes. Actualmente, con la derogación de dicho Código y a partir de la entrada en 
vigencia del Código de Convivencia Ciudadana, la figura del Merodeo fue reemplazada por la de Conducta sospechosa.

7 Casos de desaparición de jóvenes y de víctimas de homicidio policial (gatillo fácil).

8 Categoría local: policía.

9 Carlos La Mona Jiménez, cantante de cuarteto, ritmo popular característico de la música de Córdoba.

\section{Macarena Roldán}

Licenciada en Psicología por la Universidad Nacional de Córdoba (UNC), Argentina. Doctoranda en Psicología, con beca del CONICET y la UNC. Actualmente, desarrolla sus actividades en el Centro de Investigaciones y Estudios sobre Cultura y Sociedad (CIECSCONICET/UNC) y es Docente Adscripta en la Facultad de Psicología (UNC). Sus estudios se inscriben en el campo de la psicología social y política. Trabaja líneas de investigación vinculadas con la subjetividad política, la acción colectiva y los procesos de resistencia juvenil frente a la violencia policial. Es autora de artículos publicados en la Revista Latinoamericana de Estudios sobre Cuerpos, Emociones y Sociedad (Argentina), Persona y Sociedad (Chile) y Methaodos. Revista de Ciencias Sociales (España). Últimas publicaciones: M. Roldán. 20r8. "Acción colectiva juvenil y procesos de subjetivación política: el caso de la Marcha de la Gorra en Córdoba (Argentina)". Methaodos. Revista de Ciencias Sociales 6(2): 252-262; M. Roldán. 20i9. "Emocionalidad política y procesos de subjetivación en la acción colectiva juvenil: la 'Marcha de la Gorra' en Córdoba-Argentina". Revista Latinoamericana de Estudios sobre Cuerpos, Emociones y Sociedad, ir(29): 58-70. M. Roldán. 2019. "Más de una década de la Marcha de la Gorra en Córdoba, Argentina: un análisis diacrónico de sus demandas". Persona y Sociedad 33(I): Io8-I32. 